\title{
Specific aspects on the adequate selection of electric equipment intended for use in potentially explosive atmospheres
}

\author{
Lucian Moldovan ${ }^{1 *}$, Mihai Magyari ${ }^{1}$, Dragoș Fotău ${ }^{1}$, and Clementina Sabina Moldovan ${ }^{2}$ \\ ${ }^{1}$ INCD INSEMEX, Department for Safety of Explosionproof Equipment and Installations, 32-34 \\ G-ral Vasile Milea Street, Petrosani, Romania \\ ${ }^{2}$ University of Petrosani, Department of Environmental Engineering and Geology, 20 University \\ Street, Petrosani, Romania
}

\begin{abstract}
When using electrical equipment in installations operating in hazardous areas endangered by potentially explosive atmospheres, care shall be taken also to the selection of such equipment. The correct selection of equipment for use in potentially explosive atmospheres must be considered in the design phase of an installation and verified in the mounting phase. Equipment intended for use in potentially explosive atmospheres must be designed, manufactured and placed on the EU market considering the provisions of the ATEX Directive 2014/34/EU. In order to adequately select the electrical equipment, the provisions of the regulations in force must be considered together with the provisions of applicable standards.
\end{abstract}

\section{Introduction}

For an explosion to occur, an explosive atmosphere and a source of ignition need to co-exist. The second basic principle, according Directive 1999/92/EC, for prevention and protection against explosions, consists in the avoidance of the ignition of explosive atmospheres $[1,2]$. This principle also considers the possible ignition sources of electrical equipment.

When electrical equipment is installed in areas where explosive concentrations and quantities of flammable gases, vapours or dusts may be present in the atmosphere, protective measures are applied to reduce the likelihood of explosion due to ignition by arcs, sparks or hot surfaces, produced either in normal operation or under specified fault conditions [2].

Electrical installations in hazardous areas shall also comply with the appropriate requirements for installations in non-hazardous areas (even though the requirements for nonhazardous areas are insufficient for installations in hazardous areas) and to other specific requirements so as to avoid the ignition of the explosive atmosphere [3].

One of the first measures needed to be taken into account, in case of using electric equipment in installations designed to operate in explosive atmospheres, is to try locating much of the electrical equipment in less hazardous or non-hazardous areas [3, 4].

\footnotetext{
* Corresponding author: lucian.moldovan@insemex.ro
} 
Electrical equipment and materials should be installed and used within their electrical ratings. In particular, care should be taken to ensure that the voltage and frequency are appropriate to the supply system in which the equipment is used and that the temperature classification has been established for the correct voltage, frequency, etc. [3]

To facilitate the selection of appropriate electrical equipment and the design of suitable electrical installations, hazardous areas generated by flammable substances in form of gases, vapours and mists are divided into zones 0,1 and 2 according EN 60079-10-1 [5, 6].

Electrical equipment and wiring in hazardous areas has to be selected and installed in accordance with SR EN 60079-14 and the additional requirements for the particular type of protection [3].

All equipment shall be installed in accordance with its documentation. A specific care should be considered in case of replaceable items, such as lamps (these must be of the correct type and rating). On completion of the erection, initial inspection of the equipment and installation shall be carried out in accordance with EN 60079-14 [3, 7].

In order to correctly install or extend an existing installation to operate in potentially explosive atmospheres generated by the presence of flammable substances in the form of gases, vapours and mists the following information, should be available [3]:

- area classification documents (according SR EN 60079-10-1) showing the classification and extent of the hazardous areas including the zoning (zoning plans);

- where applicable, gas, vapour classification in relation to the group or subgroup of the electrical equipment;

- temperature class or ignition temperature of the gas or vapour involved;

- external influences and ambient temperature.

- manufacturer's instructions for selection, installation and initial inspection;

- documents for electrical equipment with specific conditions of use (e.g. for equipment with certificate numbers which have the suffix " $X$ ");

- descriptive system document for the intrinsically safe system;

- details of any relevant calculation (e.g. purging rates for instruments houses);

- manufacturer's declaration of conformity.

- necessary information to ensure correct installation of the equipment provided in a form which is suitable to the personnel responsible for this activity (according SR EN 60079-0 and Directive 2014/34/EU). Consideration should be given to obtaining information for maintenance and repair;

- documentation relating to the suitability of the equipment for the area and environment to which it will be exposed (e.g. temperature ratings, type of protection, IP rating, corrosion resistance);

- the plans showing types and details of wiring systems;

- records of selection criteria for cable entry systems for compliance with the requirements for the particular type of protection;

- drawings and schedules relating to circuit identification;

- records of the initial inspection.

\section{Selection of equipment}

In order to properly select the electrical equipment for use in hazardous areas (in form of flammable gases, vapours and mists), the following information is required [3]:

- classification of the hazardous area including the equipment protection level requirements where applicable;

- where applicable, gas or vapour classification in relation to the group or subgroup of the electrical equipment;

- temperature class or ignition temperature of the gas or vapour involved; 
- $\quad$ intended application of the equipment;

- $\quad$ external influences and ambient temperature.

Also, when selecting equipment designed for use in potentially explosive atmospheres, the provisions of Directive 1999/92/EC (transposed in Romanian legislation by GD 1058/2006) and Directive 2014/34/EU (transposed in Romanian legislation by GD 245/2016) shall be considered $[1,2,8]$.

\subsection{Selection of equipment according to Ex classified zones}

\subsubsection{Equipment for use in zone 0}

In zone 0 only equipment of category $1 \mathrm{G}$, according ATEX Directive 2014/34/EU, shall be used $[1,8]$.

In zone 0 is admitted only the equipment with EPL Ga. Electrical equipment and circuits can be used in zone 0 if they are in accordance with SR EN 6007911 (intrinsic safety "ia"), SR EN 60079-18 (encapsulation "ma"), SR EN 60079-26 (two independent types of protection of EPL Gb), and SR EN 60079-28 (Protection of equipment and transmission systems using optical radiation "op is") [3]. Also, portable detection sensors, according the last edition of SR EN 60079-1 (flameproof enclosure "da") are allowed in zone 0 (is supplied from intrinsic safety circuits in level "ia").

\subsubsection{Equipment for use in zone 1}

Electrical equipment is allowed to be used in zone 1 if it is constructed in accordance with the requirements for zone 0 . Also, equipment of category $2 \mathrm{G}$, according ATEX Directive 2014/34/EU, can be used [1, 8].

In zone 1 the equipment with EPL Gb can also be used. Electrical equipment and circuits can be used in zone 1 (with EPL Gb) if they are made considering one or more of the following types of protection (see Table 1) [3]:

Table 1. Specific types of protection and levels of protection for use in zone 1 [3]

\begin{tabular}{|l|l|l|}
\hline Type of protection & $\begin{array}{l}\text { Level of } \\
\text { protection }\end{array}$ & Specific standard \\
\hline Flameproof enclosures & "db" & SR EN 60079-1 \\
\hline Pressurized enclosures & "pxb" or "pyb" & SR EN 60079-2 \\
\hline Powder filling & "qb" & SR EN 60079-5 \\
\hline Oil immersion & "ob" & SR EN 60079-6 \\
\hline Increased safety & "eb" & SR EN 60079-7 \\
\hline Intrinsic safety & "ib" & SR EN 60079-11 \\
\hline Encapsulation & "mb" & SR EN 60079-18 \\
\hline $\begin{array}{l}\text { Protection of equipment } \\
\text { and transmission systems } \\
\text { using optical radiation }\end{array}$ & $\begin{array}{l}\text { "op is" } \\
\text { "op sh" }\end{array}$ & SR EN 60079-28 \\
\hline $\begin{array}{l}\text { Fieldbus intrinsically safe } \\
\text { concept (FISCO) }\end{array}$ & & SR EN 60079-27 \\
\hline
\end{tabular}




\subsubsection{Equipment for use in zone 2}

Electrical equipment is allowed to be used in zone 2 if it is constructed in accordance with the requirements for zone 0 and zone 1 . Equipment of category $1 \mathrm{G}, 2 \mathrm{G}$ and also $3 \mathrm{G}$, according ATEX Directive 2014/34/EU, can be used [1,8].

In zone 2 the equipment with EPL Gc can also be used. Electrical equipment and circuits can be used in zone 2 (with EPL Gc) if they are made considering one or more of the following types of protection (see Table 2) [3]:

Table 2. Specific types of protection and levels of protection for use in zone 2 [3]

\begin{tabular}{|l|l|l|}
\hline Type of protection & $\begin{array}{l}\text { Level of } \\
\text { protection }\end{array}$ & Specific standard \\
\hline Flameproof enclosures & "dc" & SR EN 60079-1 \\
\hline Pressurized enclosures & "pxz" & SR EN 60079-2 \\
\hline Oil immersion & "oc" & SR EN 60079-6 \\
\hline Increased safety & "ec" & SR EN 60079-7 \\
\hline Intrinsic safety & "ic" & SR EN 60079-11 \\
\hline Encapsulation & "mc" & SR EN 60079-18 \\
\hline $\begin{array}{l}\text { Protection of equipment } \\
\text { and transmission systems } \\
\text { using optical radiation }\end{array}$ & $\begin{array}{l}\text { “op is" "op sh" } \\
\text { "op pr" }\end{array}$ & SR EN 60079-28 \\
\hline Type of protection "n" & nA, nR, nC & SR EN 60079-15 \\
\hline
\end{tabular}

\subsection{Selection of equipment according to the ignition temperature of the gas or vapour}

Electrical equipment shall be so selected that its maximum surface temperature not to reach the ignition temperature of any gas or vapour which may be present $[3,9]$.

For equipment included in temperature classes, the relationship between the temperature class of the equipment and the auto-ignition temperature of gas or vapor (as mentioned in SR EN 60079-20-1) is indicated in table 3 [3].

Table 3. Relationship between the temperature classes, surface temperatures and ignition temperature [3]

\begin{tabular}{|c|c|c|}
\hline $\begin{array}{c}\text { Temperature class of } \\
\text { electrical equipment }\end{array}$ & $\begin{array}{c}\text { Maximum surface temperature of } \\
\text { electrical equipment }\left({ }^{\circ} \mathbf{C}\right)\end{array}$ & $\begin{array}{c}\text { Ignition temperature } \\
\text { of gas or vapour }\left({ }^{\circ} \mathbf{C}\right)\end{array}$ \\
\hline $\mathrm{T} 1$ & 450 & $>450$ \\
\hline $\mathrm{T} 2$ & 300 & $>300$ \\
\hline $\mathrm{T} 3$ & 200 & $>200$ \\
\hline $\mathrm{T} 4$ & 135 & $>135$ \\
\hline $\mathrm{T} 5$ & 100 & $>100$ \\
\hline $\mathrm{T} 6$ & 85 & $>85$ \\
\hline
\end{tabular}


If the marking of the electrical equipment does not include an ambient temperature range, the equipment shall be used only within the temperature range $-20^{\circ} \mathrm{C}$ to $+40^{\circ} \mathrm{C}$. If the marking of the electrical equipment includes an ambient temperature range, the equipment shall only be used within this range $[3,10]$.

\subsection{Selection of equipment according grouping}

Electrical equipment shall be selected considering the specific gas/vapor classification. The classification for most of the flammable gases/vapours can be found in the specific standard SR EN 60079-20-1.

In Table 2 is presented the relation between the gas/vapor classification and the accepted equipment subgroup [3].

Table 4. Relationship between gas/vapour classification and equipment subgroup [3]

\begin{tabular}{|c|c|}
\hline Gas/vapour classification & Equipment subgroup \\
\hline IIA & IIA, IIB or IIC \\
\hline IIB & IIB or IIC \\
\hline IIC & IIC \\
\hline
\end{tabular}

\subsection{External influences}

Electrical equipment shall be selected and installed so that it is protected against external influences (e.g. extremely low or high temperatures; solar radiation; pressure conditions; corrosive atmosphere; vibrations, mechanical impacts, friction or abrasion; wind; painting processes; chemicals; water and moisture; dust; plants, animals, insects etc.) which could adversely affect the explosion protection [3].

Precautions shall be taken to prevent foreign bodies falling vertically into the ventilation openings of vertical rotating electrical machines [3].

Where equipment is subject to prolonged humidity and wide temperature variations that may lead to condensation affecting the type of protection, the equipment should be provided with suitable measures to ensure satisfactory prevention of condensation or draining of any condensate [3].

\subsection{Other considerations}

Each type of protection has a specific principle and an associated technical solution. Thus, not all types of protection can be applied to protect a certain equipment. In fact, a specific type of protection cannot cover all types of equipment. On the other hand, multiple types of protection can be used, in order to achieve protection to explosion of an equipment.

The type of protection " $d$ " can be used in case of equipment generating electrical arcs and sparks. As a consequence, this type of protection can be used also in case of equipment not producing electrical arcs and sparks [3]. This type of protection can be used in case of electric motors, luminaires, push buttons, catalytic sensors, heating resistances, junction boxes, electric panels, different types of transducers etc.

The type of protection intrinsic safety "i" can be applied only for low power equipment [3]. It cannot be used for power circuits. It is used only for low current equipment like sensors, data transmission and monitoring equipment, lanterns etc. It is very important to consider the use of intrinsic safety barriers when designing intrinsic safety circuits.

The type of protection increased safety is used only for equipment not producing electrical arcs and sparks in normal operation [3]. It is used for junction boxes, electrical motors (with squirrel cage rotor), some types of luminaires etc. This type of protection is commonly used 
together with the type of protection flameproof enclosure for equipment producing electrical arcs and sparks (for example a push buttons - " $d$ " for the button itself - the compartment where the electrical contact is opened and closed and increased safety "e" for the compartment where the terminals are located; an electric motor - "d" for the main compartment of the motor and " $\mathrm{e}$ " for the terminal box).

The type of protection pressurization " $p$ " uses a protection gas (at a pressure higher than the pressure of the surrounding explosive atmosphere) to ensure that the explosive atmosphere will not get in contact with an ignition source inside the enclosure [3]. This type of protection can be applied to electric motors (large ones), control desks, analysers etc.

The type of protection encapsulation uses an encapsulant (compound or resin) that closes and seals the equipment to be protected so that the surrounding explosive atmosphere not to get in contact with a possible ignition source [3]. This type of protection cannot be used for equipment with moving parts. Examples of equipment protected with the type of protection "m" are solenoids, electronic circuit boards, LED luminaires (encapsulation of LEDs and drivers), electronic ballasts, etc.

These considerations are important also in the design phase of an installation, when conceiving the technical sheets of the equipment to be used.

\section{Selection of radiating equipment}

Optical radiation (especially focused radiation), can become an ignition source. Radiation from high intensity light sources (e.g. photo flash lamps or some LEDs) can be absorbed by particles, in certain conditions, and may become an ignition source [3].

Laser radiation (for example, signalling, telemeters, surveying, range-finders) may be so high (the energy or power density even of the unfocused beam at long distances) that ignition is possible [3].

Lasers or other continuous wave sources (in case of electrical equipment) of EPL "Ga"and"Gb" must not exceed the following values [3] :

- $\quad 5 \mathrm{~mW} / \mathrm{mm}^{2}$ or $35 \mathrm{~mW}$ (continuous wave lasers and other continuous wave sources)

- $\quad 0,1 \mathrm{~mJ} / \mathrm{mm}^{2}$ (pulse lasers or pulse light sources with pulse intervals of at least $5 \mathrm{~s}$ ).

Lasers or other continuous wave sources of electrical equipment of EPL "Gc" shall not exceed the following values [3]:

- $\quad 10 \mathrm{~mW} / \mathrm{mm}^{2}$ or $35 \mathrm{~mW}$ (continuous wave lasers and other continuous wave sources)

- $\quad 0,5 \mathrm{~mJ} / \mathrm{mm}^{2}$ (pulse lasers or pulse light sources).

The values mentioned in SR EN 60079-28 are also considered [10].

These requirements apply also for equipment installed outside hazardous area but radiating into the hazardous area $[3,10]$.

\section{Selection of ultrasonic equipment}

In case of ultrasonic equipment installed in hazardous area (or installed outside, but radiating into the hazardous area) the output parameters (for EPL "Ga", "Gb", "Gc") must not exceed the following values [3]:

- $\quad 0,1 \mathrm{~W} / \mathrm{cm}^{2}$ and $10 \mathrm{MHz}$ for continuous sources.

- average power density $0,1 \mathrm{~W} / \mathrm{cm}^{2}$ and $2 \mathrm{~mJ} / \mathrm{cm}^{2}$ for pulse sources.

A relaxation for the $0,1 \mathrm{~W} / \mathrm{cm}^{2}$ value is mentioned in the last edition of SR EN 60079-0. The sound pressure level (SPL) is now the parameter to be considered.

For gases, according SR EN 60079-0 the following limits, regarding the SPL shall not be exceeded [10]:

- $10 \mathrm{MHz}$ 
- $\quad$ for continuous sources - SPL $170 \mathrm{~dB}(\operatorname{ref} 20 \mu \mathrm{Pa})$;

- for pulse sources (averaged over a $1 \mathrm{~s}$ interval) -Average SPL of $170 \mathrm{~dB}$ (ref 20 $\mu \mathrm{Pa}$ ). For An SPL of $170 \mathrm{db}$ (at $20 \mu \mathrm{Pa}$ as reference pressure level) represents a sound intensity of $10 \mathrm{~W} / \mathrm{cm}^{2}$, a significant relaxation from the former limit of $0,1 \mathrm{~W} / \mathrm{cm}^{2}$.

For liquids, according SR EN 60079-0 the following limits, regarding the SPL shall not be exceeded [10]:

- $10 \mathrm{MHz}$

- $\quad$ for continuous sources - Power density $40 \mathrm{~W} / \mathrm{cm}^{2}$;

- $\quad$ for pulse sources (averaged over a $1 \mathrm{~s}$ interval) - Average power density 40 $\mathrm{W} / \mathrm{cm}^{2}$.

\section{Selection of cable entry devices, adapters and blanking elements}

An important aspect that must be considered, in order to maintain the explosion protection characteristics of an equipment designed for use in potentially explosive atmospheres is to adequately select the cable glands. This is because some equipment is certified together with cable entries (cable glands) and for other equipment, the manufacturer decided to certify the equipment without cable glands. For the latter case, the designer of the installation or the person(s) involved in the selection of equipment shall chose suitable cable glands.

The first aspect to be considered is to correctly select the cable glands according the type of cable. That is because not all cables are round. For example, in case of trace heating cables (with type of protection "e"), most of them are flat cables and the cable gland sealing element must have a specific shape to fit the cable in such a manner that to maintain the type and degree of protection.

The use of other materials to match the cable diameter to the cable gland (like sealing tape, heat shrink tube etc.) is not permitted [3].

Cable glands used for electrical equipment must comply to the requirements of SR EN 60079-0. When selecting the cable glands, the type of protection of the equipment/part of equipment where the cable gland is installed must be preserved. The selection of cable glands must consider the provision of Table 5 [3].

Cable glands installation shall be made such that after installation they are capable of being released or dismantled only by the use of a tool [3].

The cable glands designed for use at ambient temperature ranges different from $-20{ }^{\circ} \mathrm{C}$ to $40{ }^{\circ} \mathrm{C}$ and/or operating temperatures higher than $80^{\circ} \mathrm{C}$ require certification documents for these aspects [3].

To prevent pulling and twisting forces of the cable to be transmitted to the conductor terminations inside the enclosure, additional clamping might be required $[3,10]$.

In order to avoid lateral tension that may compromise the seal around the cable these must be routed straight from the cable gland [3].

In case of braided or armoured cables terminated within the cable gland, the cable gland components intended to retain and secure the cable braid or armour should be able to be released only by the use of a tool [3].

Where the threaded entry or hole size is different to that of the cable gland, a threaded adapter complying with Table 5 can be fitted [3]. 
Table 5. Selection of cable glands/adapters/blanking elements according to the type of protection [3]

\begin{tabular}{|c|c|c|c|}
\hline \multirow{2}{*}{$\begin{array}{l}\text { Type of protection of the } \\
\text { equipment/part of } \\
\text { equipment where the } \\
\text { cable gland / adapter / } \\
\text { blanking element is } \\
\text { installed }\end{array}$} & \multicolumn{3}{|c|}{$\begin{array}{c}\text { Type of protection of the cable gland cable gland / adapter / } \\
\text { blanking element }\end{array}$} \\
\hline & Ex “d" & Ex "e" & Ex “n” \\
\hline Ex "d" - see also 5.1 & $X$ & & \\
\hline Ex “e” & $\mathrm{X}$ & $X$ & \\
\hline $\begin{array}{l}\text { Ex "i" and Ex "nL" - } \\
\text { Group II }\end{array}$ & $\mathrm{X}$ & $X$ & $\mathrm{X}$ \\
\hline Ex "m" & \multicolumn{3}{|c|}{$\begin{array}{l}\text { Ex "m" is not normally applied to wiring connections. The } \\
\text { protection technique for connections shall suit the wiring system. }\end{array}$} \\
\hline $\begin{array}{l}\text { Ex "n" except Ex "nL" } \\
\text { For Ex"nR" see also } 5.2\end{array}$ & $\mathrm{X}$ & $\mathrm{X}$ & $\mathrm{X}$ \\
\hline Ex “o" & \multicolumn{3}{|c|}{$\begin{array}{l}\text { Ex "o" is not normally applied to wiring connections. The } \\
\text { protection technique for connections shall suit the wiring system. }\end{array}$} \\
\hline Ex "px" and Ex "py" & $\mathrm{X}$ & $\mathrm{X}$ & \\
\hline$E x$ “pz” & & & $\mathrm{X}$ \\
\hline Ex “q” & \multicolumn{3}{|c|}{$\begin{array}{l}\text { Ex "q" is not normally applied to wiring connections. The } \\
\text { protection technique for connections shall suit the wiring system. }\end{array}$} \\
\hline
\end{tabular}

Unused entries in the enclosure must be closed and sealed by blanking elements in accordance with Table 5. The blanking element must be chosen so as to maintain the degree of protection IP 54 or that required by the location, whichever is higher. Blanking elements must be constructed so that it can be released or removed only by the use of a tool [3].

In case of flameproof enclosures, the adapters are not to be used together with blanking elements $[3,11,12]$.

\subsection{Supplementary requirements for flameproof enclosure " $d$ "}

When the cables enter into the flameproof equipment via flameproof bushings through the wall of the enclosure (which are part of the equipment - indirect entry), the compartment of the bushings outside the flameproof enclosure must be protected by a compatible type of protection [3]. For example, one part of the bushings can be placed in the flameproof compartment and the other part can be within a terminal compartment with type of protection flameproof enclosure or type of protection "e".

For Ex "d" cable glands when clamping by the sealing ring (compression) is used in case of braided or armoured cable, these must be so that the braid or armour to be terminated in the gland and compression to take place on the inner cable sheath. [3].

Threaded flameproof cable glands, adapters or blanking elements (parallel threads) may be provided with a sealing washer between the entry device and the flameproof enclosure. The condition that must be accomplished is that regarding the thread engagement after the fitting of the washer (at least five full threads). Adequate grease (nonsetting, non-metallic and non-combustible) may be used (earthing between the two parts must be maintained) [3].

In case of taper threads, the connection must be made wrench tight $[3,11]$.

Addition of holes or alteration to thread form, if needed, must be completed by the manufacturer or certified workshops and shall be in compliance with the certification 
documents. In case of threaded entry or hole size different to that of the cable gland, a flameproof threaded adapter can be used if it complies with SR EN 60079-1 and the thread engagement requirements. Unused cable entries must be closed with a flameproof blanking element according SR EN 60079-1(that can be fitted directly to the hole without using any threaded adapter), complying with thread engagement requirements and secured against loosening $[3,12]$.

Cable entry system of flameproof enclosures must comply with one of the following [3]:

a) Cable glands sealed with setting compound (barrier cable glands) according SR EN 60079-1 and certified as equipment [3];

b) Cables and glands meeting all the following requirements [3]:

- cable glands are according SR EN 60079-1 (certified as equipment);

- the cables used are sheathed with thermoplastic, thermosetting, or elastomeric material. Cables are circular and compact with extruded bedding or sheath. Only nonhygroscopic fillers are accepted.

- the connected cable is at least $3 \mathrm{~m}$ in length;

c) indirect cable entry using combination of flameproof enclosure with a bushing and increased safety terminal box [3];

d) mineral-insulated metal-sheathed cable with or without plastic outer covering with appropriate flameproof cable gland complying with SR EN 60079-1 [3];

e) flameproof sealing device (for example a sealing chamber) specified in the equipment documentation or complying with SR EN 60079-1 and employing a cable gland appropriate to the cables used. The sealing device shall incorporate compound or other appropriate seals which permit stopping around individual cores. The sealing device shall be fitted at the point of entry of cables to the equipment [3].

Because flame propagation of flame may occur through the interstices between the strands of standard stranded conductors, or between individual cores of a cable, measures have to be taken to avoid this. In some cases, a restricted breathing test for cables is required to be performed [3].

\subsection{Supplementary requirements for restricted breathing enclosure " $n R$ "}

The sealing of "nR" enclosures has to maintain the restricted breathing properties of the enclosure [3].

Where the cable used is not part of the certificate and/or instruction manual and is not effectively filled, it may be necessary to use a cable gland or other method (e.g. epoxy joint, shrinking tube) which seals around the individual conductors of the cable to prevent leakage from the enclosure [3].

A suitable sealing washer shall be fitted between the cable gland and the enclosure. Conduit or tapered threads will require the use of a thread sealant [3].

\section{Conclusions}

In the paper were presented relevant aspects related to the adequate selection of electric equipment intended for use in potentially explosive atmospheres. The focus was on electrical equipment designed for use in potentially explosive atmospheres generated by flammable gas, vapours or mists.

In the first part of the paper were presented specific aspects regarding the protection to explosion and in the second part the criteria to select electrical equipment according the Ex classified zone, the ignition temperature of the gas or vapour, grouping, external influences and other considerations.

The third and fourth part of the paper presented some aspects regarding the selection of radiating and ultrasonic equipment. 
The last part of the paper presented some important and specific aspects regarding the selection of cable entry devices, adapters and blanking elements, together with additional requirements for the type of protection flameproof enclosure " $d$ " and restricted breathing " $n R$ ".

All the presented aspects have a specific importance for the personnel involved in designing of installations, selection of equipment and mounting of equipment in installations operating in potentially explosive atmospheres.

\section{References}

1. Directive 1999/92/EC of the European Parliament and of the Council of 16 December 1999 on minimum requirements for improving the safety and health protection of workers potentially at risk from explosive atmospheres (1999)

2. M. Paraian, S. Burian, N. Vatavu, F. Paun, MATEC Web of Conferences 305, 00009 (2020)

3. SR EN 60079-14, Explosive atmospheres - Part 14: Electrical installations design, selection and erection (2014)

4. Standard SR EN 1127-1, Explosive atmospheres. Explosion prevention and protection. Basic concepts and methodology (2019)

5. Standard SR EN 60079-10-1, Explosive atmospheres. Classification of areas. Explosive gas atmospheres (2015)

6. V. M. Pasculescu, N. I. Vlasin, E. Ghicioi, G. D. Florea, M. C. Suvar, EEMJ, 18, 889 (2019)

7. Standard SR EN 60079-17, Explosive atmospheres. Electrical installations inspection and maintenance (2014)

8. Directive 2014/34/EU of the European Parliament and of the Council of 26 February 2014 on the harmonisation of the laws of the Member States relating to equipment and protective systems intended for use in potentially explosive atmospheres (recast) (2014)

9. L. Moldovan, S. Burian, M. Magyari, M. Darie, D. Fotau, EEMJ, 16, 1317 (2017)

10. Standard SR EN 60079-0, Explosive atmospheres - Part 0: Equipment - General requirements (2018)

11. Standard SR EN 60079-1, Explosive atmospheres - Part 1: Equipment protection by flameproof enclosures "d" (2015)

12. D. Fotau, M. Magyari, L. Moldovan, M. Rad, C. Colda, EEMJ, 18, 811 (2019) 